\title{
Which statistics should tropical biologists learn?
}

\author{
Natalia Loaiza Velásquez ${ }^{1}$, María Isabel González Lutz ${ }^{2}$ \& Julián Monge-Nájera ${ }^{3}$
}

1. Biología Tropical, Universidad de Costa Rica, 2060 San José, Costa Rica; natalia.loaiza@ucr.ac.cr

2. Escuela de Estadística, Universidad de Costa Rica, 2060 San José, Costa Rica; mariaisabel.gonzalezlutz@ucr.ac.cr

3. Laboratorio de Ecología Urbana, UNED, 2050 San José, Costa Rica; Universidad de Costa Rica, 2060 San José, Costa Rica; julianmonge@gmail.com

Received 13-IX-2010. C Corrected 03-II-2011. Accepted 01-III-2011.

\begin{abstract}
Tropical biologists study the richest and most endangered biodiversity in the planet, and in these times of climate change and mega-extinctions, the need for efficient, good quality research is more pressing than in the past. However, the statistical component in research published by tropical authors sometimes suffers from poor quality in data collection; mediocre or bad experimental design and a rigid and outdated view of data analysis. To suggest improvements in their statistical education, we listed all the statistical tests and other quantitative analyses used in two leading tropical journals, the Revista de Biología Tropical and Biotropica, during a year. The 12 most frequent tests in the articles were: Analysis of Variance (ANOVA), Chi-Square Test, Student's T Test, Linear Regression, Pearson's Correlation Coefficient, Mann-Whitney U Test, Kruskal-Wallis Test, Shannon's Diversity Index, Tukey's Test, Cluster Analysis, Spearman's Rank Correlation Test and Principal Component Analysis. We conclude that statistical education for tropical biologists must abandon the old syllabus based on the mathematical side of statistics and concentrate on the correct selection of these and other procedures and tests, on their biological interpretation and on the use of reliable and friendly freeware. We think that their time will be better spent understanding and protecting tropical ecosystems than trying to learn the mathematical foundations of statistics: in most cases, a well designed one-semester course should be enough for their basic requirements. Rev. Biol. Trop. 59 (3): 983-992. Epub 2011 September 01.
\end{abstract}

Key words: education of tropical biologists, statistical courses, free statistics software, tropical biology journals.

Tropical biologists study the richest and often the most endangered biodiversity in the planet and in these times of climate change and mega-extinctions, the need for efficient, good quality research is more pressing than in the past. Previous authors have mentioned the need to improve the statistical training that tropical biologists receive, in order to reach those goals of efficiency and quality (Monge-Nájera 2002).

However, the statistical component in research published by tropical authors has been qualified as suffering from three problems: poor quality in data collection; mediocre or bad experimental design and a rigid and outdated view of data analysis (Fielding \& Lauckner 1992).
In comparison with the scientific leaders, tropical statisticians are few, isolated and not always properly trained, having for example a poor grasp of the concept of variability and its usefulness in biology. Some scientific journals that publish in this field accept articles that lack appropriate descriptions of the experimental design and in some cases, $70 \%$ of the articles have incorrect statistical analyses (Camacho 1997).

Some problems detected by the authors of Camacho's (1997) compilation are not so serious today, thanks to the Internet, which provides acceptable statistical software for free and helps statisticians from tropical countries to keep abreast of new developments and in 
contact with colleagues. However, the key to the problem lies in education and progress is slow in this field. The results of statistics courses taught to biology students are often unsatisfactory, and students too often end up hating statistics and being unable to select and apply appropriate test and procedures (Camacho 1997).

To summarize the problem, tropical biologists are not being taught the statistics they really need. The objective of this article is to identify the statistical tests that are most frequently used in the current literature of tropical biology, and to use that information to recommend an updated syllabus to all institutions that educate tropical biologists.

\section{MATERIALS AND METHODS}

We listed all the statistical tests and other quantitative analyses used in two leading tropical journals, the Revista de Biología Tropical and Biotropica. For the Revista we reviewed all of the articles from editions 56-4 (December 2008) to 57-4 (December 2009), not including the supplements. For Biotropica, we used only the articles included in the "Papers" section from editions 40-4 (July 2008) to 41-4 (July 2009).

\section{RESULTS}

We found that the articles in both journals used a large number of unusual statistics, but that each of these highly specialized procedures and tests was used very few times (Appendix).

The 12 most frequent tests in the articles were: Analysis of Variance (ANOVA), Chi-Square Test, Student's T Test, Linear Regression, Pearson's Correlation Coefficient, Mann-Whitney U Test, Kruskal-Wallis Test, Shannon's Diversity Index, Tukey's Test, Cluster Analysis, Spearman's Rank Correlation Test and Principal Component Analysis (Table 1).

TABLE 1

Statistical tests and other quantitative procedures that were used more than once during the studied year

\begin{tabular}{lclc}
\multicolumn{1}{c}{ Revista de Biología Tropical } & \multicolumn{1}{c}{ Biotropica } \\
\multicolumn{1}{c}{ Test or procedure } & Trequency or procedure & \multicolumn{1}{c}{ Frequency } \\
ANOVA & 50 & ANOVA & 31 \\
Chi-Square Test & 26 & Chi-Square Test & 26 \\
Student's T Test & 23 & Student's T Test & 25 \\
Linear Regression & 18 & Linear Regression & 17 \\
Pearson's Correlation Coefficient & 17 & Pearson's Correlation Coefficient & 16 \\
Kruskal-Wallis Test & 16 & Mann-Whitney U Test & 14 \\
Shannon's Diversity Index & 13 & Generalized Linear Models & 13 \\
Abundance & 11 & Spearman's Rank Correlation Test & 11 \\
Richness & 11 & Akaike's Information Criterion & 10 \\
Tukey's Test & 11 & Bray-Curtis Coefficient & 10 \\
Cluster Analysis & 10 & Tukey's Test & 9 \\
Spearman's Rank Correlation Test & 10 & Kruskal-Wallis Test & 8 \\
Principal Components Analysis & 9 & Multiple Regresion Analysis & 8 \\
Bray-Curtis Coefficient & 9 & ANCOVA & 7 \\
Canonical Correspondence Analysis & 8 & Nonparametric Multidimensional Scaling & 7 \\
Duncan Test & 8 & Richness & 7 \\
Kolmogorov-Smirnov Test & 8 & Wilcoxon Test & 7 \\
ANCOVA & 7 & Jackknife Statistics & 6 \\
Chao Index & 6 & Kolmogorov-Smirnov Test & 6
\end{tabular}


TABLE 1 (Continued)

Statistical tests and other quantitative procedures that were used more than once during the studied year

\begin{tabular}{|c|c|c|c|}
\hline \multicolumn{2}{|l|}{ Revista de Biología Tropical } & \multicolumn{2}{|l|}{ Biotropica } \\
\hline Test or procedure & Frequency & Test or procedure & Frequency \\
\hline Mann-Whitney Test & 6 & Monte Carlo Test & 6 \\
\hline UPGMA & 6 & Abundance & 5 \\
\hline Linear Correlation Analysis & 5 & ANOSIM & 5 \\
\hline Jaccard Index & 5 & Cluster Analysis & 5 \\
\hline Morisita Index & 5 & Least Squares & 5 \\
\hline Variation Coefficient & 5 & MANOVA & 5 \\
\hline Euclidean Distance & 4 & Morisita Index & 5 \\
\hline Dunnett's T3 Test & 4 & Principal Components Analysis & 5 \\
\hline Jackknife Statistics & 4 & Amova & 4 \\
\hline Least Significant Difference & 4 & Bonferroni Correction & 4 \\
\hline Margalef Index & 4 & Fst Statistics & 4 \\
\hline SIMPER & 4 & Kaplan Meier Method & 4 \\
\hline Student-Newman-Keuls Test & 4 & Mantel Test & 4 \\
\hline Bonferroni Correction & 4 & Bootstrap & 3 \\
\hline ANOSIM & 3 & Chao Index & 3 \\
\hline Correlacion Matrix & 3 & Fisher's Exact Test & 3 \\
\hline Frecuency & 3 & G Test & 3 \\
\hline Laverne Test & 3 & Jaccard Index & 3 \\
\hline Levene Test & 3 & Logistic Regresion & 3 \\
\hline Modal Progression Analysis & 3 & Maximum Likihood & 3 \\
\hline Simpson Index & 3 & Poisson Distribution & 3 \\
\hline Discriminant Function Analysis & 2 & Regression Analysis & 3 \\
\hline Hardy-Weimberg Equilibrium & 2 & Relative Growth Rate & 3 \\
\hline Evenness Index & 2 & Shannon Evenness Index & 3 \\
\hline Robertson and Hill' F Statistics & 2 & SIMPER & 3 \\
\hline Wright's F Statistics & 2 & Simpson Index & 3 \\
\hline Fisher's Alpha Diversity Index & 2 & Backward Elimination & 2 \\
\hline F Statistic & 2 & Bayesian Analysis & 2 \\
\hline Fulton's Correlation Test & 2 & Canonical Correspondence Analysis & 2 \\
\hline Generalized Linear Models & 2 & Correlation Matrix & 2 \\
\hline Wilks’ Lambda & 2 & Dunn Test & 2 \\
\hline Logistic Regression & 2 & Fixation Index & 2 \\
\hline MANOVA & 2 & Hosmer and Lemeshow's Goodnes of Fit Test & 2 \\
\hline Least Squares & 2 & Kendall Tau Rank Correaltion Test & 2 \\
\hline Multiple Dismensional Scaling & 3 & Linear Correlation & 2 \\
\hline Non-Parametric Multidimensional Scaling & 2 & Log Rank Test & 2 \\
\hline Fisher's Exact Test & 2 & Least Significant Difference & 2 \\
\hline Multiple Regression & 2 & Minimun Convex Polygon Method & 2 \\
\hline Shapiro-Wilk Test & 2 & Monte Carlo Simulation & 2 \\
\hline \multirow[t]{4}{*}{ Wilcoxon Test } & 2 & Multidimensional Scaling & 2 \\
\hline & & Multiple Linear Regresion Model & 2 \\
\hline & & Multivarate Ordinations & 2 \\
\hline & & Odds Ratio & 2 \\
\hline
\end{tabular}


TABLE 1 (Continued)

Statistical tests and other quantitative procedures that were used more than once during the studied year

\begin{tabular}{|c|c|c|c|}
\hline \multicolumn{2}{|c|}{ Revista de Biología Tropical } & \multicolumn{2}{|l|}{ Biotropica } \\
\hline Test or procedure & Frequency & Test or procedure & Frequency \\
\hline & & Pairwise Comparisons Test & 2 \\
\hline & & Sørensen Similarity Index & 2 \\
\hline & & Wilks' Lambda & 2 \\
\hline & & UPGMA & 2 \\
\hline & & Univariate Linear Regression & 2 \\
\hline & & Chao-Sorensen Index & 2 \\
\hline & & Canonical Analysis of Principal Coordinates & 2 \\
\hline
\end{tabular}

\section{DISCUSSION}

In tropical ecosystems, a few species are very common, while most species are rare; and in our sample, the same applies to statistical procedures. There is no justification to burden students with a knowledge of procedures that they will seldom, if ever, use; if the need arises, such procedures can be applied by professional statisticians. On the other hand, the main mathematical procedures were almost the same in both journals, even though Biotropica is more limited to terrestrial ecology, while the Revista publishes articles from a variety of fields in marine and terrestrial biology, as well as on the conservation of tropical ecosystems.

This gives us some confidence to recommend that statistical education of tropical biologists be based on learning when to use the dozen tests that they are more likely to need in their professional life (top of Table 1). The mathematical procedures involved in those tests, as well as any mathematical proof to justify those procedures, must be eliminated from the courses and left to professional statisticians. Highly useful tests such as Chi-Squared and the $\mathrm{G}$ test are simple, but more complex ones -such as multivariate tests- can also be understood from a practical perspective without need for the subjacent mathematics.

Descriptive statistics is also something everyone needs, but again only to understand what averages, standard deviation and the like mean. Learning the algorithms to calculate them is not necessary because computers already "know" how to do it for us.

A frequent weakness in most articles, not only in tropical biology but in all fields and nations, is the poor selection of graphics that has become omnipresent after the introduction of computer spreadsheets. But this problem is easy to identify (a simple guide to good statistical graphics is here: www.biologiatropical. ucr.ac.cr).

Students should also learn that the statistician must be consulted before collecting the data, and not afterwards, when it may be too late. They should not finish their statistical courses hating statistics, as we know is the case in some institutions, but rather feeling confident that they can select the correct procedure and apply it, as also found by previous authors (Garfield and Ben-Zvi 2007, Metz 2008).

Software is another field in which current education clearly fails. Excellent free software is available to everyone in the Internet, yet most universities pay huge yearly amounts in licenses of professional software for students. Very good programs that are fit for tropical biologists are available in http://faculty.vassar.edu/lowry/VassarStats.html and in other addresses (e.g. http://statpages.org/, www. freestatistics.info and www.macstats.org). Professional programs should only be bought for professional statisticians.

Students should also learn that statistics has space for humor, as shown by Gary C. Ramseyer's First Internet Gallery of Statistics 
Jokes (http://my.ilstu.edu/ gcramsey/Gallery. html), and that the motto of the guild is "Rubbish in, rubbish out". They must always put mathematics at the service of biology and not the opposite; they should understand that only controlled experiments can identify cause and effect relationships; if this requirement is not met, no statistical procedure will (James \& McCulloch 1990).

Additionally, it is of the greatest importance that:

1. Statistics be taught within the career's subject courses (for example, as part of biology or medicine courses, instead of being a separate course) or at least, that all examples used in courses be from the career's field (Metz 2008).

2. Related subjects, such as distribution, center and spread of data, be learned as a single concept (Garfield \& Ben-Zvi 2007).

Currently, students can pass statistics courses with good marks even when they cannot understand statistics (Garfield \& Ben-Zvi 2007, Metz 2008). Furthermore, they cannot apply statistical procedures outside the contexts in which they learned them and cannot understand the meaning of statistical tests and graphics (Garfield \& Ben-Zvi 2007).

Every year unnecessary statistics textbooks continue to be written and published everywhere, despite the fact that all the information needed by students is freely available in Internet. Apart from that, almost all statistics textbooks available today are basically the same, a situation that would not be so bad if these they had the information that the students need, but a comparison of contents in books being published now and those from half a century ago will show little difference except for the addition of multivariate tests. Not surprisingly, student learning also is poor practically everywhere (Garfield \& Ben-Zvi 2007, Metz 2008).

In conclusion, statistical education for tropical biologists must abandon the old syllabus based on the mathematical side of statistics and concentrate on the correct selection of procedures and tests, on their biological interpretation and on the use of reliable and friendly freeware. In most cases, a well designed one-semester course should be enough for them. It is a matter of common sense: their time will be better spent understanding and protecting tropical ecosystems than trying to learn the mathematical foundations of statistics.

\section{RESUMEN}

Los biólogos tropicales estudian la biodiversidad más rica y amenazada del planeta, y en estos tiempos de cambio climático y mega-extinción, la necesidad de investigación de buena calidad es más acuciante que en el pasado. Sin embargo, el componente estadístico en la investigación publicada por los autores tropicales adolece a veces de baja calidad en la toma de datos, mal diseño experimental y una visión anticuada del análisis de datos. Para sugerir mejoras en la enseñanza de la estadística, hicimos una lista de todas las pruebas estadísticas y otros análisis cuantitativos aplicados en dos de las principales revistas tropicales, la Revista de Biología Tropical y Biotropica, durante un año. Las 12 pruebas más frecuentes en los artículos fueron: Análisis de Varianza (ANDEVA), Chi-cuadrado, t de Student, Regresión lineal, Coeficiente de Correlación de Pearson, U de Mann-Whitney, Kruskal-Wallis, Índice de diversidad de Shannon, Prueba de Tukey, Análisis de Conclomerados, Correlación de Spearman y Análisis de Componentes Principales. Concluimos que la enseñanza de la estadística para los biólogos tropicales debe abandonar el viejo plan de estudios basado en el lado matemático de la estadística y concentrarse en (1) la correcta selección de estos y otros procedimientos y pruebas, (2) su interpretación biológica y (3) la utilización de programas de fácil uso. En la mayoría de los casos, un curso bien diseñado de un semestre bastaría para sus necesidades básicas.

Palabras clave: educación de biólogos tropicales, cursos de estadística, software libre para estadística, revistas de biología tropical.

\section{REFERENCES}

Camacho, J. (ed.). 1997. Biometrical education: problems, experiences and solutions. Universidad Nacional and Centro Agrícola Tropical de Investigación y Enseñanza, Heredia, Costa Rica.

Fielding, W.J. \& F.B. Lauckner. 1992. Biometric training in developing countries: Caribbean experiences. Statistician 41: 105-111. 
Garfield, J. \& D. Ben-Zvi. 2007. How students learn statistics revisited: a current review of research on teaching and learning statistics. Intern. Stat. Rev. 75: 372-396.

James, F.C. \& C.E. McCulloch. 1990. Multivariate analysis in ecology and systematics: Panacea or Pandora's box? Annu. Rev. Eciol. Syst. 21: 129-166.
Monge-Nájera, J. 2002. How to be a tropical scientist (50 ${ }^{\text {th }}$ anniversary editorial). Rev. Biol. Trop. 50: 19-23.

Metz, A.M. 2008. Teaching statistics in biology: using inquiry-based learning to strengthen understanding of statistical analysis in biology laboratory courses. CBE_Life Sci. Educ. 7: 317-326. 
APPENDIX

Quantitative procedures used only once in the examined volumes

\begin{tabular}{|c|c|}
\hline Revista de Biología Tropical & Biotropica \\
\hline Andrews Graph & Accelerated Bias Corrected Confidence Limits \\
\hline Autocorrelacion Coefficient & Acumulation Curve Analysis \\
\hline Autocorrelacion Function & Additive Main Effect and Multiplicative Interactions Model \\
\hline Binomial Probabilistic Model & Ancillary Variable Correlation \\
\hline Binomial Proportion & Anderson-Darling Test \\
\hline Bioplots Graph & ANODEV \\
\hline Bootstrap & Assignment Test \\
\hline Box Cox's Better Transformation & Association Matrix of Kulczynsky \\
\hline Canonical Variate Analysis & Autocorrelation Function \\
\hline Cochran Test & Average Effect Size \\
\hline Complete Independence Test & Average Variance Effective Size \\
\hline Cophenetic Correlation & B-Error Distribution With Log Link Function \\
\hline Correlation Test & Best Subset Multiple Regression \\
\hline Partitioning of Chi-Square, Method of & Binomial Error Distribution \\
\hline Diametric Distribution & Binomial Test \\
\hline Dice Index of Disimilarity & Chao-Jaccard Similarity Index \\
\hline Disperssion Index & Chao-Jaccard-Raw- Abundance Based Index \\
\hline Dunn Test & Circular Statistic \\
\hline Factorial Correspondence Analysis & Compositional Analysis \\
\hline $\begin{array}{l}\text { Fit of Data For Log-Series, Lognormal, Geometric and } \\
\text { Broken Strick Models }\end{array}$ & Contiguity Index \\
\hline Form Index SHAPE & Contingency Table Analysis \\
\hline Friedman Test & Contrast Analysis \\
\hline Gamma Probabilistic Model With Log Link Funcion & Cormak-Jolly-Seber Models \\
\hline Gauch and Whittakernon's Linear Regresion Model & Correlated Mating Model \\
\hline Generalized Discriminant Analysis & Dendograms \\
\hline Geometric Distribucion Model & Density \\
\hline K Parameter of Negative Binomial Distribution & Detrended Correspondence Analysis \\
\hline Kendrall's Tau B Test & Disimilarity Index \\
\hline Likelihood Ratio Test & Disimilarity Matrix \\
\hline Logaritmic Distribution Model & Distance Dissimilarity Coefficient \\
\hline Log-Linear Analysis & Disturbance Index \\
\hline Log-Normal Distribution Model & Dunnet T3 Test \\
\hline Macarthur and Levene Index Modified by Pianka & Dunn’s Test \\
\hline Manhattan Distance Matrix & Edge Contrast \\
\hline Mantel Test & Elasticity Analysis \\
\hline Meyer I Distribution & Euclidean Distances \\
\hline Meyer II Distribution & Expectation Maximization Numerical Method \\
\hline Monte Carlo Test & Exponential Model \\
\hline Morisita-Horn Index & F Statistic \\
\hline Multiple Discriminant Analysis & F Watson-Williams Test \\
\hline Multiple Regression Analysis & Fisher's F Statistic \\
\hline Multivariate Analysis & Fisher's Least Singnificant Diference Test \\
\hline Multivariate Analysis of Covariance & Fisher's Omnibus Test \\
\hline
\end{tabular}


APPENDIX (Continued)

Quantitative procedures used only once in the examined volumes

Revista de Biología Tropical

Negative Binomial Distribution

Newman-Keuls Test

Normal Probabilistic Model With Indentity Link Function

Normalized Difference Vegetation Index

Probability Transitions Matrix

Randomization Analysis

Randomized Block Analysis

Rank-Abundance Plot

Redundance Analysis

Residual Analysis

Ripley's K Test

Sba K -Weiner Index

Scheffe Test

Schoener Overlar Index

Sign Test

Similarity Matrix

Single-Factor Anlaysis of Variance

Square Cannonical Correlation

Trend Analysis

Variance Test

Wald Test

Warner Dendograma

Weibull Distribution

Z Test

\section{Biotropica}

Fixed Kernel Home Rage

Flexible Beta Linkage Method

Foundress Number

Friedman Test

Gamma Error Distribution With Log Link Funcion

Gehan's Generalized Wilcoxon Survival Analysis

Geometric Mean Weigth of Prey

Greenhouse Geisser's E

Hardy-Weimberg Equilibrium

HOF Model

Hybrid Multidimensional Scaling

Individual Based Rarefaction Curves

Interclass Correlation Coefficient

K Hat Estimate of Conditional Kapa Coefficient

Kernel Density

Kishino-Hasegawa Test

Kruskal's Measures of Stress

Kullback-Leibler Information

Levine's Index

Levine's Niche-Breadth Index

Linear Autocorrelation Coefficient

Log Likelihood Test

Logistic-Link Error Distribution

Log-Likelihood Ratio

Lowess Regression

Manly's Selection Index

Mantel Correlation Coefficients

Mantel Correlation Comparisons Mantel's R

Mantel Correlograms

Mao Tau Estimator

Mao Tau Function

Mao-Tau Simple Based Rarefaction Curves

Mardia-Watson-Wheeler Test

Markov Chain Monte Carlo MCMC

Matrix Randomizations

Maximun Parsimony

Mayfield Method

Mean Czechanowski Index

Mean Pianka Index

Mean Square Error

Minimazing Yield Parameter Estimates

Minimum Model

Minimun Area Probabilities MAP

Mlmm PQL Function 
APPENDIX (Continued)

Quantitative procedures used only once in the examined volumes

\section{Biotropica}

Mode Clustering Index

Moment Core Analysis

Monte Carlo Based Kruskal Wallis H Test

Monte Carlo Permutations

Monte Carlo Randomization

Multiple Post Hoc Comparison

Multivariate Mantel Correlograms

Nei's Diversity Index

Newton-Rapson Numerical Method

Non Linear Regresion Models

Overall Population Structure Analysis

Overdispersion Parameter

Paetkau Method

Pairwise Correlations

Pairwise Population Differentiation Test

Path Coefficient

Pearson Partial Correlation

PERMANOVA

Permutation Method

Quasi-Binomial Distribution

Quasilikelihood Akaike's Information Criterion

Randomization Test

Rarefaction Analysis

Rayleigh Test

Regression Coefficient

Relatedness Coefficient

Renkonnen Index

Ricker Function

Rosario Randomization Algorithm

Runs Test

Shapiro Wilk Test

Shared Species Analysis

Similarity Matrix

Simple/ Partial Mantel Test

Sorensen Index

Standardized Ripley's K Function

Steinhays Similarity Coefficient

Stepwise Regression Model

Structural Equation Modeling

Sum Test

SUNIM Index

Suvival Function

T2 Hotelling Test

Templeton Test

Time Since Making Model 
APPENDIX (Continued)

Quantitative procedures used only once in the examined volumes

Triangular Similarity Matrix

Two Generator Model

Type III Analysis

Variance Ratio Test

Variance-Covariance Matrix

Variation Coefficient

Vulnerability Index

Wald Statistic

Wald Statistic Log-Rank Test

Wilson-Shimida Index

Wishart's Objective Function

Wright's Fixation Index 